Cory M. Yamashita

Ruud A. W. Veldhuizen

\section{Swept under the carpet? The role of mucociliary clearance in ventilator-induced lung injury}

Received: 15 September 2010

Accepted: 16 September 2010

Published online: 28 October 2010

(C) Copyright jointly held by Springer and ESICM 2010

This editorial refers to the article available at: doi:10.1007/s00134-010-2056-5.

C. M. Yamashita - R. A. W. Veldhuizen

Departments of Physiology and Pharmacology, Medicine, University of Western Ontario, London, ON N6A 5C1, Canada e-mail: cyamash@uwo.ca

C. M. Yamashita · R. A. W. Veldhuizen

Critical Illness Research, Lawson Health Research Institute, London, ON N6A 5C1, Canada

R. A. W. Veldhuizen (

Lawson Health Research Institute, Room E4-146,

268 Grosvenor Street, London, ON N6A 4V2, Canada

e-mail: rveldhui@uwo.ca

Mechanical ventilation (MV) remains one of the major areas of intensive research in critical care and respiratory medicine [1]. This intervention acts as a life-saving tool in a diverse range of clinical scenarios, but is associated with a host of potentially deleterious side-effects. Its widespread use in the intensive care setting underscores the importance of investigating both causes and mechanisms by which this supportive treatment may be harmful. Experimental and clinical studies have focussed on the effects of mechanical ventilation on either causing direct lung injury, propagating existing lung injury or predisposing the lung to subsequent complications.

The ability of mechanical ventilation to cause injury to a healthy lung has been termed ventilator-induced lung injury (VILI) and is based on numerous animal studies
$[2,3]$. Ventilation strategies causing repeated alveolar collapse and over-stretching of alveolar units have been shown to lead to VILI. A robust body of literature has emerged to offer insight into pathophysiologic mechanisms by which this phenomenon occurs, including effects on alveolar epithelial permeability, formation of hyaline membranes, alterations of surfactant, infiltration of neutrophils, release of inflammatory mediators, elevated alveolar protease activity and a variety of other biochemical processes [4-6]. Although many of the ventilation strategies used in these animal studies would not be used under clinical circumstances, these models have provided insight into the role of MV in the proposed mechanisms leading to the propagation of lung injury in humans.

The prototypic example of how mechanical ventilation contributes to the propagation of lung injury can be observed in the setting of acute lung injury (ALI) and its more severe form, acute respiratory distress syndrome (ARDS) [7]. ALI and ARDS are defined by the presence of hypoxaemia and decreased lung compliance in the absence of heart failure, with mechanical ventilation providing an essential component of the supportive therapy [8]. It should be noted that animal studies of VILI, as well as preclinical observations in animals with ALI, provided the rationale and the basic scientific foundation for a National Institutes of Health (NIH)-sponsored trial comparing low tidal volume $(6 \mathrm{ml} / \mathrm{kg})$ versus conventional tidal volume $(12 \mathrm{ml} / \mathrm{kg})$ strategies in patients with ARDS [9]. This landmark trial demonstrated a reduction in mortality in patients ventilated with lower tidal volumes and, although published nearly a decade ago, still stands out as a singular success story among a sea of failed interventions in ALI/ ARDS [10]. Ultimately, this trial unequivocally demonstrated that this supportive treatment may in fact be harmful if administered injudiciously.

In contrast to the studies that have focussed on the propagation of lung injury in ALI/ARDS, the concept of 
mechanical ventilation predisposing the lung to subsequent insults has received far less attention. Nevertheless, epidemiologic studies have demonstrated that prolonged ventilation is associated with an increased risk of ventilator-associated pneumonia, a significant clinical problem that is associated with high morbidity and high mortality $[11,12]$. The ability of bacteria to colonize and circumvent multiple innate host defence mechanisms represents a key step in this pathophysiologic process. Impairment in any of these host defence systems may result in greater susceptibility to pneumonia, leading to further inflammation, influx of neutrophils and other alterations to lung homeostatic mechanisms resulting in progressive respiratory failure.

In the current issue of Intensive Care Medicine, Piccin and colleagues [13] raise the possibility that mechanical ventilation may, in fact, directly affect one aspect of respiratory defence mechanisms, the mucociliary system. In a series of in vivo rabbit experiments using different modes of mechanical ventilation (including low tidal volume, high tidal volume and high pressure ventilation), the investigators have attempted to demonstrate that mechanical ventilation using high volume and high pressure may lead to deleterious changes in the large proximal airway mucociliary system compared with lower tidal volume ventilation. Although they noted a significant decrease in tracheal mucus secretion across all ventilated groups, only animals ventilated with continual high mean airway pressures demonstrated a significant reduction in ciliary beating frequency in ex vivo tracheal tissue specimens when compared pre and post ventilation. Unfortunately, the authors were unable to demonstrate additional functional consequences of impaired mucociliary clearance by way of an in situ charcoal particle transport technique. The authors speculated based on their findings that the mucociliary alterations observed in the high pressure ventilation cohort occurred as a result of tissue hypoperfusion caused by elevated intrathoracic pressures and high airway flows throughout the respiratory cycle.

Although several related observations were made approximately 15 years ago $[14,15]$, the findings of the current study represent a largely under-reported phenomenon within the spectrum of VILI, which is distinct from the traditional dogma of distal airway and alveolarbased injury. As with all initial animal-based observations of this nature, more in-depth in vivo studies, and possibly clinical studies, will be required to verify and expand these findings. At an experimental level, details regarding the proposed mechanism, beyond that of elevated intrathoracic pressures (and compromised tissue blood flow), accounting for the changes, are of considerable interest. A wider variety of ventilation strategies, prolonged periods of ventilation and addition biochemical outcomes may elucidate whether some or all of the morphologic and functional changes in the mucociliary epithelium could be attributable to relatively simple biomechanical effects such as elevated shear and stress forces, or if there are possible signal transductions within the large airway that contribute to these alterations.

The bedside relevance of the observation by Piccin and colleagues is, at this stage, unclear. Nevertheless, it is tempting to speculate that changes in mucociliary clearance induced by mechanical ventilation may herald a significant clinical impact such as alteration in host susceptibility to infections or prolonged intubations due to secretion retention. Further studies testing such a hypothesis are of significant clinical interest and may add yet another piece of the puzzle to our understanding of the complexity of this iatrogenic injury.

\section{References}

1. Antonelli M, Azoulay E, Bonten M, Chastre J, Citerio G, Conti G, De Backer D, Lemaire F, Gerlach H, Hedenstierna G, Joannidis M, Macrae D, Mancebo J, Maggiore SM, Mebazaa A, Preiser JC, Pugin J, Wernerman J, Zhang H (2010) Year in review in Intensive Care Medicine 2009. Part III: mechanical ventilation, acute lung injury and respiratory distress syndrome, pediatrics, ethics, and miscellanea. Intensive Care Med 36:567-584

2. Dreyfuss D, Saumon G (1998) Ventilator-induced lung injury: lessons from experimental studies. Am J Respir Crit Care Med 157:294-323
3. Tierney DF (2003) Ventilator-induced lung injury occurs in rats, but does it occur in humans? Am J Respir Crit Care Med 168:1414-1415

4. Tremblay LN, Slutsky AS (1998) Ventilator-induced injury: from barotrauma to biotrauma. Proc Assoc Am Physicians 110:482-488

5. Maruscak AA, Vockeroth DW, Girardi B, Sheikh T, Possmayer F, Lewis JF, Veldhuizen RA (2008) Alterations to surfactant precede physiological deterioration during high tidal volume ventilation. Am J Physiol Lung Cell Mol Physiol 294:L974-L983

6. Verbrugge SJ, Lachmann B (1999) Mechanisms of ventilation-induced lung injury: physiological rationale to prevent it. Monaldi Arch Chest Dis 54:22-37
7. Brower RG, Fessler HE (2000) Mechanical ventilation in acute lung injury and acute respiratory distress syndrome. Clin Chest Med 21:491-510, viii

8. Bernard GR, Artigas A, Brigham KL, Carlet J, Falke K, Hudson L, Lamy M, Legall JR, Morris A, Spragg R, the Consensus Committee (1994) The American-European consensus conference on ARDS: definitions, mechanisms, relevant outcomes, and clinical trial coordination. Am J Respir Crit Care Med 149:818-824 
9. Brower RG, Matthay MA, Morris A, Schoenfeld D, Thompson BT, Wheeler A, The Acute Respiratory Distress Syndrome Network (2000) Ventilation with lower tidal volumes as compared with traditional tidal volumes for acute lung injury and the acute respiratory distress syndrome. N Engl J Med 342:1301-1308

10. Bosma KJ, Lewis FJ (2007) Emerging therapies for treatment of acute lung injury and acute respiratory distress syndrome. Expert Opin Emerg Drugs $12: 461-477$
11. Leroy OA, Meybeck A, d'Escrivan T, Devos P, Kipnis E, Gonin X, Georges H (2004) Hospital-acquired pneumonia in critically ill patients: mortality risk stratification upon onset. Treat Respir Med 3:123-131

12. McEachern R, Campbell GD Jr (1998) Hospital-acquired pneumonia: epidemiology, etiology, and treatment. Infect Dis Clin North Am 12:761-779

13. Piccin VS et al. (2010) Effects of different mechanical ventilation strategies on the mucociliary system. Intensive Care Med. doi: 10.1007/s00134-010-2056-5
14. Konrad F, Schreiber T, Grunert A, Clausen M, Ahnefeld FW (1992) Measurement of mucociliary transport velocity in ventilated patients. Shortterm effect of general anesthesia on mucociliary transport. Chest 102:1377-1383

15. Konrad F, Schiener R, Marx T, Georgieff M (1995) Ultrastructure and mucociliary transport of bronchial respiratory epithelium in intubated patients. Intensive Care Med 21:482-489 